\title{
Effect of ankle foot orthosis on gait parameters and functional ambulation in patients with stroke
}

\author{
Serdar Kesikburun, ${ }^{1}$ Ferdi Yavuz, ${ }^{2}$ Ümüt Güzelküçük, Evren Yaşar, ${ }^{1}$ Birol Balaban ${ }^{3}$ \\ ${ }^{1}$ Gülhane Military Medical Academy, Department of Physical Medicine and Rehabilitation, Turkish Armed Forces Rehabilitation Center, Ankara, Turkey \\ ${ }^{2}$ Department of Physical Medicine and Rehabilitation, Fizyocare Physical Therapy and Rehabilitation Center, Ankara, Turkey \\ ${ }^{3}$ Department of Physical Medicine and Rehabilitation, Lefke European University, Northern Cyprus
}

Received: January 2016 Accepted: May 2016

\begin{abstract}
Objectives: This study aims to investigate the effect of ankle foot orthosis (AFO) on temporospatial parameters, ankle kinematics, and functional ambulation level in patients with stroke.

Patients and methods: Records of 286 adult patients with stroke assessed in the gait and motion analysis laboratory between April 2005 and January 2013 were reviewed. The data of 28 patients ( 16 males, 12 females; mean age $43.2 \pm 15.9$ years; range 20 to 72 years) who were analyzed with and without AFO during the same session were selected for the study. Temporospatial parameters (walking speed, cadence, opposite foot contact, double support time, single support time, step time, and step length) and ankle kinematics (ankle dorsiflexion at initial contact and midswing) were measured using the Vicon 512 motion analysis system. The video and medical records of patients were examined to determine their ambulation level according to Functional Ambulation Category.

Results: Walking speed, cadence, and ankle dorsiflexion at initial contact and midswing were significantly increased while walking with AFO compared to walking barefoot $(\mathrm{p}<0.05)$. There were significant reduction in step time and significant increase in step length and opposite foot contact with AFO on the affected side $(\mathrm{p}<0.05)$. Single support time reduced significantly with AFO on the unaffected side $(\mathrm{p}<0.05)$. Functional Ambulation Category score improved significantly with use of AFO $(\mathrm{p}<0.05)$.
\end{abstract}

Conclusion: The use of AFO has positive effects on gait parameters and functional ambulation in patients with stroke.

Keywords: Ambulation; ankle foot orthosis; gait; hemiplegia; stroke.

Sensorimotor impairments including muscle weakness, impaired selective motor control, abnormal movement synergies, spasticity, and proprioceptive deficits lead to various gait disturbances in patients with hemiplegia after stroke. ${ }^{[1]}$ Ankle foot orthoses (AFOs) are commonly prescribed for those patients to enhance gait pattern and improve safety. Ankle foot orthoses have been reported to improve foot clearance during swing, ankle position at heel strike and ankle stability during stance. ${ }^{[2]}$ Positive effects of AFOs on mobility, walking ability and balance after stroke have been demonstrated. ${ }^{[3]}$

A three-dimensional biomechanical gait analysis is the best way to understand the complex multifactorial gait dysfunction in patients with hemiplegia. ${ }^{[1]}$ It allows the quantification aspects of the locomotor pattern. ${ }^{[4]}$ This retrospective study presents a long-term experience in AFO usage in hemiplegic gait at a tertiary rehabilitation center gait laboratory. The effect of an AFO on temporospatial parameters, ankle kinematics and functional ambulation level in patients with stroke has been investigated.

\section{PATIENTS AND METHODS}

The records of 286 adult patients with stroke assessed in Gait and Motion Analysis Laboratory at Turkish Armed Forces Rehabilitation Center during an eight-year period (April 2005 - January 2013) were reviewed. Among these patients, the temporospatial and kinematic data of 28 patients (16 males, 12 females; mean age $43.2 \pm 15.9$ years;

Corresponding author: Serdar Kesikburun, MD. GATA TSK Rehabilitasyon Merkezi, Fizik Tedavi ve Rehabilitasyon Kliniği, 06800 Bilkent, Ankara, Turkey e-mail: serdarkb@gmail.com 
range 20 to 72 years) who had been analyzed under barefoot and AFO conditions during the same session were included in the study. The data of sex, age, time after stroke at the time of gait analysis, height, weight and affected side were noted from the medical records. All patients included in the study used the same type of AFO. It was a custom-made non-hinged thermoplastic solid AFO (Figure 1), which were chosen after considering individual clinical needs and fit by a qualified practitioner in gait analysis. The Local Ethics Committee of Gülhane Military Medical Academy approved the study protocol. The study was conducted in accordance with the principles of the Declaration of Helsinki.

Gait analysis was performed using a threedimensional, seven-camera, VICON 512 motion measurement system (Oxford Metrics Ltd., Oxford, UK). The VICON Clinical Manager software was used for calculating and plotting data. The following procedures were implemented routinely in our gait laboratory. Fifteen reflective markers were placed on specific anatomic landmarks bilaterally on the subject's pelvis, thighs, shanks and feet according to the marker protocol of Davis et al. ${ }^{[5]}$ Anthropometric measures including height, weight, leg length and width of ankles and knees were taken for appropriate anthropometric scaling. Each subject, who was able to walk independently with or without assistive devices, was instructed to walk at a self-selected speed along a walkway with two force plates embedded in the floor. The patients were asked to walk barefoot and then with their AFO. They were allowed to use their assistive devices or supports. Temporospatial parameters including walking speed (meters per sec), cadence (steps per min), opposite foot contact (\%), double support time (sec), single support time (sec), step time (sec) and step length (meters) were selected for the analysis. In addition, the kinematic parameters of the ankle including ankle dorsiflexion at initial contact and midswing (degrees) were assessed for the study.

The video and medical records of the patients were examined to rate ambulation level of the patients according to Functional Ambulation Category (FAC). The FAC is a visual measurement categorizing patients according to basic motor skills necessary for functional ambulation. ${ }^{[6]}$ The FAC distinguishes six levels of walking ability on the basis of the amount of physical support required, ranging from "unable to walk" (FAC 0) to "able to walk independently anywhere" (FAC 5).

\section{Statistical analysis}

All statistical tests were performed using IBM SPSS Statistics software program (IBM Corp., Armonk, NY, USA) for Mac version 20.0. Whether the distributions of continuous variables were normal was determined by Kolmogorov-Smirnov test. Data are shown as the mean \pm standard deviation or median (min-max), where applicable. Paired sample t-test for variables distributed normally or Wilcoxon signed rank test for variables not distributed normally were used to compare the measurements under barefoot and AFO conditions. A $p$ value of $<0.05$ was considered statistically significant.

\section{RESULTS}

The data of 28 patients were obtained for the study. The mean age of the patients was $43.2 \pm 15.9$ years (range, 20-72 years). Mean time after stroke at the time of gait analysis was $8.4 \pm 2.3$ months (range, 3-18 months). There were 16 male (57.2\%) and 12 female (42.8\%) patients, with 16 left-sided and 12 right-sided hemiplegia. Demographic and clinical characteristics of the patients are listed in Table 1.

Walking speed and cadence were significantly increased when patients walked with an AFO compared

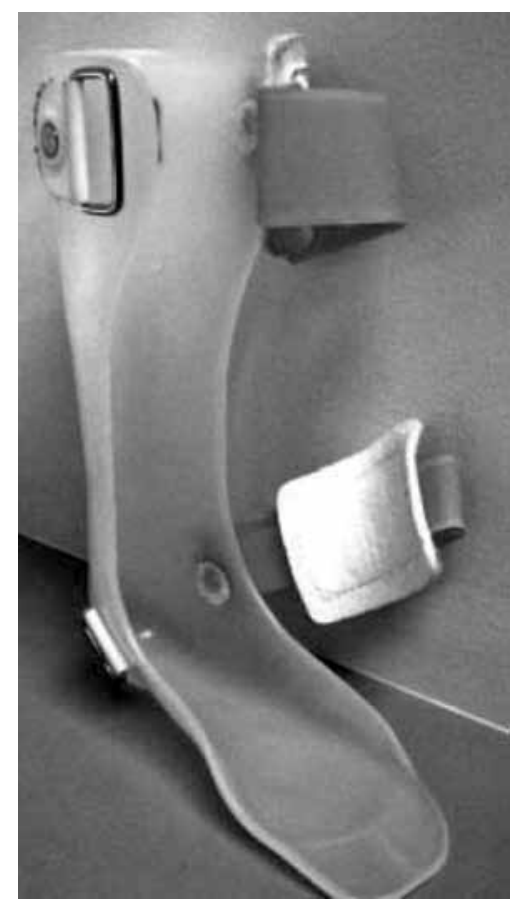

Figure 1. A custom-made nonhinged thermoplastic solid ankle foot orthoses. 
Table 1. Patients characteristics

\begin{tabular}{lccc}
\hline & $\mathrm{n}$ & $\%$ & Mean \pm SD \\
\hline $\begin{array}{l}\text { Age (year) } \\
\text { Sex }\end{array}$ & & & $43.2 \pm 15.9$ \\
$\quad$ Male & 16 & 57.2 & \\
$\quad$ Female & 12 & 42.8 & \\
Time after stroke at the time & & & $8.4 \pm 2.3$ \\
of gait analysis (month) & & & \\
Height (m) & & & $1.68 \pm 0.09$ \\
Weight (kg) & & & $73.7 \pm 15.4$ \\
Affected side & & & \\
$\quad$ Right & 12 & 42.8 & \\
$\quad$ Left & 16 & 57.2 & \\
\hline
\end{tabular}

SD: Standard deviation.

to walking barefoot $(\mathrm{p}=0.001 ; \mathrm{z}=-3.438$ and $\mathrm{p}=0.032$; $\mathrm{z}=-2.145$, respectively) (Figure 2). A significant increase in opposite foot contact, indicating a longer stance phase, was seen with use of AFO on the affected side $(p=0.014 ; z=-2.464)$. There were a significant reduction in step time and a significant increase in step length under AFO condition on the affected side $(\mathrm{p}=0.012$; $\mathrm{z}=-2.521$ and $\mathrm{p}=0.049 ; \mathrm{z}=-1.949$, respectively). There were no significant changes in opposite foot contact, step time and step length between barefoot and AFO conditions on the unaffected side $(p>0.05)$. There was not a significant decrease in double support time ( $>0.05$ ). Only on the unaffected side, single support time reduced significantly with an AFO ( $p=0.02$; $\mathrm{z}=-2.334$ ). The degrees of ankle dorsiflexion at initial contact and midswing were significantly increased when walking with an AFO $(\mathrm{p}<0.001 ; \mathrm{z}=-3.924$ and $\mathrm{p}<0.001 ; \mathrm{z}=-4.076$, respectively) (Figure 3 ). The FAC score improved significantly when patients used an AFO compared to when patients were barefoot $(p=0.002 ; z=-3.051)$. The gait parameters and the FAC score of the patients are shown in Table 2.

Walking speed was accepted as the primary outcome of the study. Based on a type I error of 0.05 , the study power was calculated 0.721 according to the primary outcome. Power analysis was performed using PS version 3 program. Two-tail test was selected for analysis Effect of interest was 0.13 .

\section{DISCUSSION}

The results from this study support the hypothesis that using an AFO improves the temporospatial parameters and ankle kinematics in patients with stroke. Functional ambulation level as measured with the FAC also increases when patients with stroke are walking with an AFO.

The most characteristic temporospatial deviation in hemiplegic gait is a decrease in walking velocity, which is an indicator of overall gait performance and associated with many other temporospatial gait parameters. ${ }^{[1]}$ The affected limb exhibits a prolonged period of swing and a reduced period of stance; as a result, decreased swing time and increased stance time are seen on the unaffected limb. ${ }^{[7]}$ Reduced step time, shorter step length and increased double support time has also been reported. ${ }^{[8,9]}$ These changes are believed to partially result from decreased walking speed. The present study shows that AFOs minimize the deviations from normal gait secondary to hemiplegia. The patients had increased walking speed and cadence when using an AFO. Step time decreased and step length increased, in parallel with increase in walking speed and swing phase of the affected limb. Double support time demonstrates a trend for decrease; however, it did not reach significance. Increased (a)

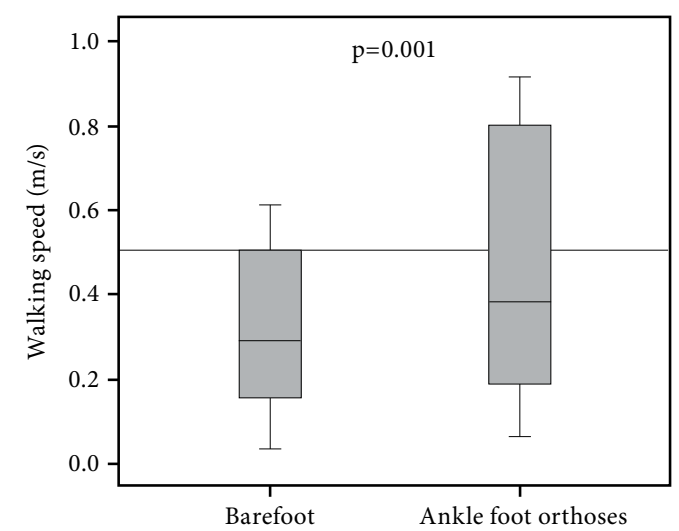

(b)

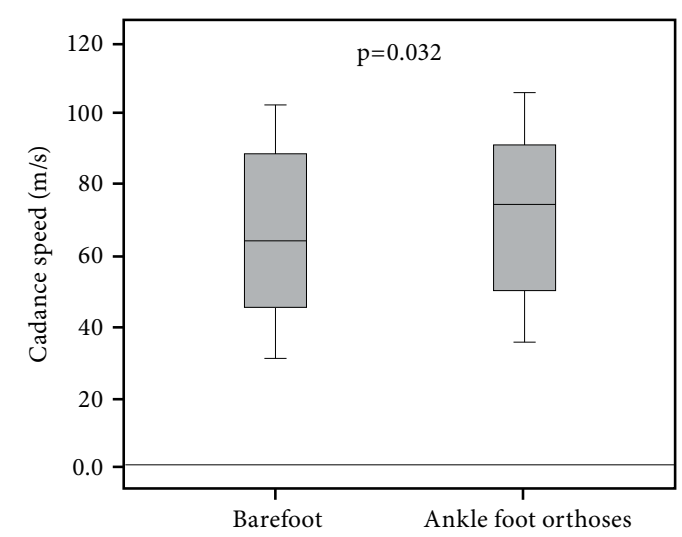

Figure 2. Walking speed (a) and cadence (b) under barefoot and ankle foot orthoses conditions. 
(a)

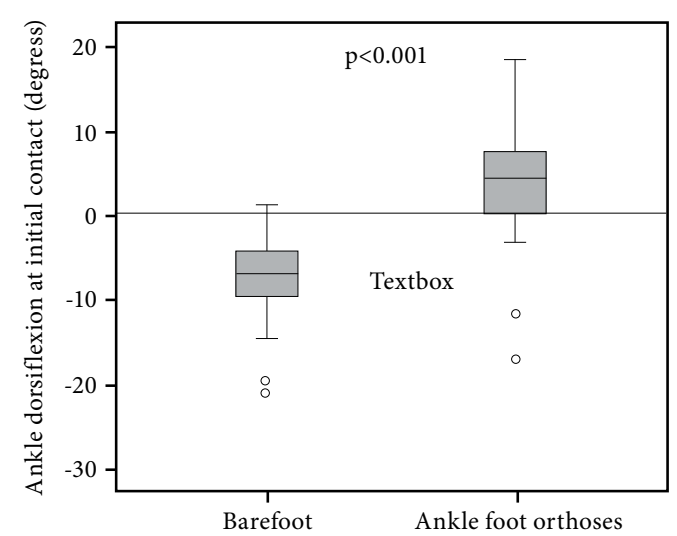

(b)

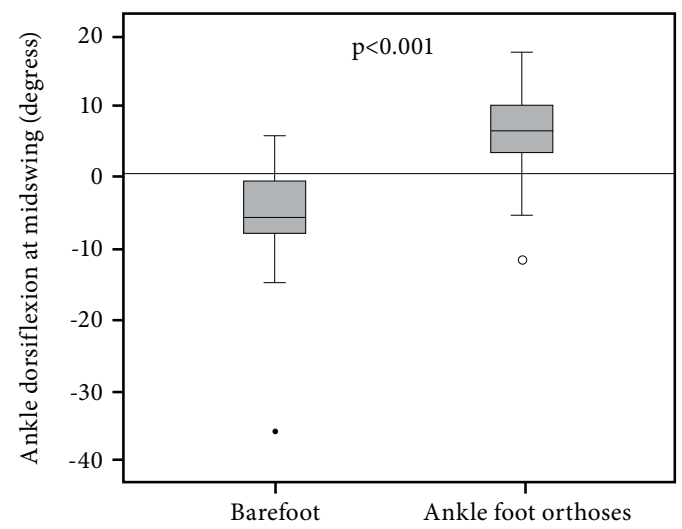

Figure 3. Ankle dorsiflexion at initial contact (a) and midswing (b) under barefoot and ankle foot orthoses conditions.

opposite foot contact and reduced single support time indicate a prolonged period of swing and a reduced period of stance on the unaffected limb, respectively, indicating an improved ankle stability during stance of the affected limb. These findings concur with previous studies. Gok et al. ${ }^{[10]}$ showed that both plastic and metallic AFOs provided an increase in walking speed, cadence and step length and decrease in step time and double support time. In a similar retrospective study, Esquenazi et al. ${ }^{[1]}$ found that walking velocity, cadence, percent stance and step length significantly increased, whereas percent swing decreased on the affected side when patients walked with an AFO. Franceschini et al. ${ }^{[12]}$ showed improvement with use of an AFO in temporospatial parameters including increases in walking speed and cadence combined with decreases in stance time and double support time in patients with chronic hemiplegia. In the study of Carse et al., ${ }^{[13]}$ patients with early stroke had an increase in walking speed, cadence and step length with a solid AFO.

Decreased dorsiflexion of the ankle is a common swing-phase kinematic disturbance in hemiplegic gait. ${ }^{[14]}$ The ankle should be normally at a neutral position (zero degree of dorsiflexion and plantar flexion) at midswing through initial contact. The last third of the swing phase is the period of gait cycle when the foot passes closest to the ground. A neutral position of the ankle during this period provides foot clearance to prevent the toes from touching the ground. ${ }^{[1]}$ The present study found that the AFO benefitted dorsiflexion in swing phase and at initial contact. This result is in line with previous studies ${ }^{[15-20]}$ that reported an increase in ankle dorsiflexion at initial contact and during swing when using an AFO.

A recent meta-analysis showed the positive effect of AFOs on mobility in patients with stroke. ${ }^{[3]}$ The FAC score of patients improved while wearing an AFO. However, the same meta-analysis found that the AFO did not affect other aspects of mobility, including timed stair climb and Timed Up \& Go test. Nolan et al. ${ }^{[21]}$ evaluated the effect of AFOs on functional ambulation using different walking assessments and found increased distance walked during the Six-Minute Walking Test and reduced time while completing the $25-\mathrm{ft}$ walk with AFO usage. The results of this study support the hypothesis that an AFO improves functional ambulation and increases the FAC score in patients with stroke.

Even though similar research has been conducted on AFO use in the literature regarding stroke rehabilitation, these studies commonly studied the effect of a specifically designed AFO in a small number of participants. The present study exhibited the long-term experience of a gait laboratory in a tertiary rehabilitation center. Gait records of a large stroke population were examined. Actually, all the patients in the study were samples from routine daily clinical practice and not subjects selected to use a specifically designed AFO. This type of solid AFO used in the study was probably the most commonly prescribed AFO in this center. Therefore, the present study confirmed the benefits of commonly prescribed AFO for patients with stroke using data from routine clinical practice.

Retrospective design is the primary limitation of this study. However, all gait assessments both under AFO 
Table 2. Gait parameters and functional ambulation level under barefoot and AFO conditions $(\mathrm{n}=28)$

\begin{tabular}{|c|c|c|c|c|c|c|c|c|}
\hline & \multicolumn{3}{|c|}{ Barefoot } & \multicolumn{3}{|c|}{ Ankle foot orthoses } & \multirow[b]{2}{*}{$t / z$} & \multirow[b]{2}{*}{$p$} \\
\hline & Mean \pm SD & Median & Min-Max & Mean \pm SD & Median & Min-Max & & \\
\hline \multicolumn{9}{|l|}{$\begin{array}{l}\text { Temporospatial } \\
\text { parameters }\end{array}$} \\
\hline Walking speed $(\mathrm{m} / \mathrm{s})$ & & 0.32 & $0.11-0.73$ & & 0.43 & $0.09-0.95$ & -3.438 & $0.001 \ddagger$ \\
\hline Cadance (steps/min) & & 68.9 & $35.7-103.0$ & & 74.1 & $38.5-100.0$ & -2.145 & $0.032 \ddagger$ \\
\hline $\begin{array}{l}\text { Opposite foot contact }(\% \\
\text { Affected side } \\
\text { Unaffected side }\end{array}$ & $55.9 \pm 13.0$ & 39.6 & $16.0-65.7$ & $57.9 \pm 7.5$ & 43.9 & $23.3-57.5$ & $\begin{array}{l}-2.464 \\
-0.737\end{array}$ & $\begin{array}{l}0.014 \ddagger \\
0.988^{\star}\end{array}$ \\
\hline $\begin{array}{l}\text { Double support time (s) } \\
\text { Affected side } \\
\text { Unaffected side }\end{array}$ & & $\begin{array}{l}0.56 \\
0.59\end{array}$ & $\begin{array}{l}0.32-1.94 \\
0.26-1.92\end{array}$ & & $\begin{array}{l}0.45 \\
0.47\end{array}$ & $\begin{array}{l}0.28-2.12 \\
0.22-2.18\end{array}$ & $\begin{array}{l}-1.044 \\
-1.413\end{array}$ & $\begin{array}{l}0.297 \ddagger \\
0.158 \ddagger\end{array}$ \\
\hline $\begin{array}{l}\text { Single support time (s) } \\
\text { Affected side } \\
\text { Unaffected side }\end{array}$ & $0.41 \pm 0.08$ & 0.60 & $0.34-1.22$ & $0.41 \pm 0.06$ & 0.57 & $0.32-0.86$ & $\begin{array}{l}-0.056 \\
-2.334\end{array}$ & $\begin{array}{l}0.956^{\star} \\
0.020 \ddagger\end{array}$ \\
\hline $\begin{array}{l}\text { Step time (s) } \\
\text { Affected side } \\
\text { Unaffected side }\end{array}$ & & $\begin{array}{l}1.04 \\
0.72\end{array}$ & $\begin{array}{l}0.48-2.28 \\
0.50-1.50\end{array}$ & & $\begin{array}{l}0.86 \\
0.67\end{array}$ & $\begin{array}{l}0.66-2.12 \\
0.44-1.36\end{array}$ & $\begin{array}{l}-2.521 \\
-1.766\end{array}$ & $\begin{array}{l}0.012 \ddagger \\
0.077 \ddagger\end{array}$ \\
\hline $\begin{array}{l}\text { Step length }(\mathrm{m}) \\
\text { Affected side } \\
\text { Unaffected side }\end{array}$ & & $\begin{array}{l}0.32 \\
0.30\end{array}$ & $\begin{array}{l}0.13-0.70 \\
0.08-0.67\end{array}$ & & $\begin{array}{l}0.37 \\
0.31\end{array}$ & $\begin{array}{l}0.14-0.65 \\
0.12-0.60\end{array}$ & $\begin{array}{l}-1.949 \\
-2.098\end{array}$ & $\begin{array}{l}0.049 \ddagger \\
0.067 \ddagger\end{array}$ \\
\hline $\begin{array}{l}\text { Kinematic parameters } \\
\text { Ankle dorsiflexion at } \\
\text { initial contact, degrees }\end{array}$ & & -6.80 & $-20.68-1.40$ & & 4.15 & $-16.67-18.40$ & -3.924 & $<0.001 \neq$ \\
\hline $\begin{array}{l}\text { Ankle dorsiflexion at } \\
\text { midswing, degrees }\end{array}$ & & -5.69 & $-36.00-5.88$ & & 6.69 & $-11.60-17.80$ & -4.076 & $<0.001 \ddagger$ \\
\hline $\begin{array}{l}\text { Functional ambulation } \\
\text { classification }\end{array}$ & & 4 & $1-5$ & & 4 & $2-5$ & -3.051 & $0.002 \ddagger$ \\
\hline
\end{tabular}

SD: Standard deviation; Min: Minimum; Max: Maximum; ${ }^{\star}$ Paired sample t-test was used to compare variables; $¥$ Wilcoxon signed rank test was used to compare variables.

and barefoot conditions were done during the same visit. Thus, potential variability in the walking performance of the patients, which may be seen in a retrospective review of the gait data obtaining on different days, was not allowed. Another limitation of the study is how long the patients had used their AFOs was not known. Findings of the study only showed the immediate effect of AFO usage on hemiplegic gait. Future studies may investigate the long-term effects of AFOs.

In conclusion, this study consists of a retrospective review of the data from selected patients with stroke at a tertiary rehabilitation center gait laboratory. The findings demonstrate that AFO improves certain temporospatial parameters and ankle kinematics of the patients. Besides that the patients had a better functional ambulation level, as measured with the FAC score, while wearing an AFO. The results from this laboratory's long-term experience confirm the beneficial effect of AFO on hemiplegic gait.

\section{Declaration of conflicting interests}

The authors declared no conflicts of interest with respect to the authorship and/or publication of this article.

\section{Funding}

The authors received no financial support for the research and/or authorship of this article.

\section{REFERENCES}

1. Balaban B, Tok F. Gait disturbances in patients with stroke. PM R 2014;6:635-42.

2. Tyson SF, Sadeghi-Demneh E, Nester CJ. A systematic review and meta-analysis of the effect of an ankle-foot orthosis on gait biomechanics after stroke. Clin Rehabil 2013;27:879-91.

3. Tyson SF, Kent RM. Effects of an ankle-foot orthosis on balance and walking after stroke: a systematic review and pooled meta-analysis. Arch Phys Med Rehabil 2013;94:1377-85.

4. Nadeau S, Betschart M, Bethoux F. Gait analysis for poststroke rehabilitation: the relevance of biomechanical analysis and the impact of gait speed. Phys Med Rehabil Clin N Am 2013;24:265-76. 
5. Davis RB III, Ounpuu S, Tyburski D, Gage JR. A gait analysis data collection and reduction technique. Hum Mov Sci 1991;10:575-87.

6. Holden MK, Gill KM, Magliozzi MR, Nathan J, Piehl-Baker L. Clinical gait assessment in the neurologically impaired. Reliability and meaningfulness. Phys Ther 1984;64:35-40.

7. Woolley SM. Characteristics of gait in hemiplegia. Top Stroke Rehabil 2001;7:1-18.

8. Roth EJ, Merbitz C, Mroczek K, Dugan SA, Suh WW. Hemiplegic gait. Relationships between walking speed and other temporal parameters. Am J Phys Med Rehabil 1997;76:128-33.

9. Bohannon RW. Gait performance of hemiparetic stroke patients: selected variables. Arch Phys Med Rehabil 1987;68:777-81.

10. Gök H, Küçükdeveci A, Altinkaynak H, Yavuzer G, Ergin S. Effects of ankle-foot orthoses on hemiparetic gait. Clin Rehabil 2003;17:137-9.

11. Esquenazi A, Ofluoglu D, Hirai B, Kim S. The effect of an ankle-foot orthosis on temporal spatial parameters and asymmetry of gait in hemiparetic patients. PM R 2009;1:1014-8.

12. Franceschini M, Massucci M, Ferrari L, Agosti M, Paroli C. Effects of an ankle-foot orthosis on spatiotemporal parameters and energy cost of hemiparetic gait. Clin Rehabil 2003;17:368-72.

13. Carse B, Bowers R, Meadows BC, Rowe P. The immediate effects of fitting and tuning solid ankle-foot orthoses in early stroke rehabilitation. Prosthet Orthot Int 2015;39:454-62.
14. Bensoussan L, Mesure S, Viton JM, Delarque A. Kinematic and kinetic asymmetries in hemiplegic patients' gait initiation patterns. J Rehabil Med 2006;38:287-94.

15. Fatone S, Hansen AH. Effect of ankle-foot orthosis on rollover shape in adults with hemiplegia. J Rehabil Res Dev 2007;44:11-20.

16. Fatone S, Gard SA, Malas BS. Effect of ankle-foot orthosis alignment and foot-plate length on the gait of adults with poststroke hemiplegia. Arch Phys Med Rehabil 2009;90:810-8.

17. Park JH, Chun MH, Ahn JS, Yu JY, Kang SH. Comparison of gait analysis between anterior and posterior ankle foot orthosis in hemiplegic patients. Am J Phys Med Rehabil 2009;88:630-4.

18. Mulroy SJ, Eberly VJ, Gronely JK, Weiss W, Newsam CJ. Effect of AFO design on walking after stroke: impact of ankle plantar flexion contracture. Prosthet Orthot Int 2010;34:277-92.

19. Lairamore C, Garrison MK, Bandy W, Zabel R. Comparison of tibialis anterior muscle electromyography, ankle angle, and velocity when individuals post stroke walk with different orthoses. Prosthet Orthot Int 2011;35:402-10.

20. Yamamoto S, Fuchi M, Yasui T. Change of rocker function in the gait of stroke patients using an ankle foot orthosis with an oil damper: immediate changes and the short-term effects. Prosthet Orthot Int 2011;35:350-9.

21. Nolan KJ, Savalia KK, Lequerica AH, Elovic EP. Objective assessment of functional ambulation in adults with hemiplegia using ankle foot orthotics after stroke. PM R 2009;1:524-9. 